\title{
Women's Rights in Human Rights Systems: Past, Present and Future ${ }^{1}$
}

\author{
NAVANETHEM PILLAY \\ United Nations High Commissioner for Human Rights
}

\begin{abstract}
'Equality includes full and equal enjoyment of all rights and freedoms. To promote the achievement of equality, legislative and other measures designed to protect or advance persons, or categories of persons, disadvantaged by unfair discrimination may be taken... The state may not unfairly discriminate directly or indirectly against anyone on one or more grounds, including race, gender, sex, pregnancy, marital status, ethnic or social origin, colour, sexual orientation, age, disability, religion, conscience, belief, culture, language and birth.'
\end{abstract}

(Sections 9(2) and 9(3) of the South African Constitution, 1996)

I thank you for this homecoming invitation that truly honours me. I am delighted to give the Dullah Omar Memorial Lecture on the topic 'The Agenda for the Promotion of the Rights of Women in the Next Decade'. Dullah Omar's leadership and commitment to democracy and human rights have greatly helped to sustain and realise the dreams of generations of South Africans. It is indeed heartwarming to know that new generations will continue to be schooled in, and motivated by, his example and wisdom.

I had the privilege to know Dullah Omar personally and retain both a deep admiration for, and fond memories of, him. One is particularly endearing to me. It concerns a stroll that he and I, returning from Robben Island, took together. At one point we stopped in front of the market stall that his wife was running. He confessed that his wife's business brought home more money than his law practice. This was somewhat unsurprising on two counts: the first stemmed from the resourcefulness and business acumen of his wife; the second depended on the fact that a significant portion of Dullah Omar's work was devoted to the poor, as well as impecunious anti-apartheid activists. I cannot forget the pride and love that made him rhapsodise about the leadership of his spouse.

As we commemorate his exceptional life, we must also celebrate the power of ordinary people and the determination of women who stood up against injustice, violence, marginalisation and tyranny. He cherished and nurtured that power. They triumphed against all odds. I am proud of having been part of that movement.

1 Sixth Dullah Omar Memorial Lecture delivered at the University of the Western Cape on 1 July 2009. 
Today I speak as the United Nations High Commissioner for Human Rights, and also as a committed and long-time advocate for women's rights and gender equality. In South Africa I co-founded the Advice Desk for the Abused that ran a shelter for victims of domestic violence. As a member of the Women's National Coalition, I worked with colleagues to ensure the inclusion in the Constitution of South Africa of the equality clause which prohibits discrimination on the basis of sex and on a number of other grounds. I also co-founded an international women's rights organisation.

At the UN International Criminal Tribunal for Rwanda, I heard women testify to atrocities of sexual violence, and saw how this violence had been used to destroy families and communities. Thus, I helped to establish the recognition of rape as one means of perpetrating genocide.

Throughout my career as a legal advocate and as a judge, I have worked hard to ensure that procedural and evidentiary rules are gender-sensitive, and take account of rights of victims and witnesses.

I have learned that equality and non-discrimination on the basis of sex are not only goals in their own right, but are essential for the achievement of all human rights for all, the realisation of sustainable human development, as well as the development of all societies. I have also learned that change comes not merely through individual endeavour, but through working collectively to achieve concrete progress.

More than 60 years have passed since the adoption of the UN Universal Declaration of Human Rights; three decades have elapsed since the Convention on the Elimination of All Forms of Discrimination against Women (CEDAW) set out legal obligations for State parties directed towards women's empowerment and rights; and in 1993 the Vienna Declaration and Programme of Action stated that the human rights of women and of the girl-child are an inalienable, integral and indivisible part of universal human rights. That same year the UN General Assembly adopted the Declaration on the Elimination of Violence against Women, and in 1994 the United Nations Commission on Human Rights established the first women-specific special procedure, the Special Rapporteur on Violence against Women. On 10 December 1999, the last human rights day of the 20th century, an Optional Protocol to the 1979 CEDAW, providing for individual petitions and inquiries, was opened for signature, ratification and accession. These tools have provided the framework for the development of international jurisprudence on the rights of women and girls.

There is no doubt that in this relatively short time-span we have also seen remarkable progress in the development and implementation of regional jurisprudence, as well as national laws, policies and programmes, directed to promoting women's equality with men.

Indeed, there is a growing acceptance that human rights, as well as the development and security of all communities, depend on the full participation of women. To borrow from economists' parlance, violence and discrimination against women are 'externalities' that the world can ill afford. As the scholar Devaki Jain has pointed out, the degree to which, and the access that, 
women have to just development is a measure of 'the stage of development of a nation'. It follows that women and their knowledge must be seen as growth agents.

Yet women throughout the world remain amongst the poorest and most marginalised, with limited access to rights, resources and opportunities. They continue to suffer multiple forms of discrimination, and endure psychological and physical violence.

Stereotypical attitudes regarding gender roles are deeply rooted in every culture. Sometimes these attitudes entrench ideas of inferiority or superiority of women and men, as well as stereotyped roles for men and women. But, over time, in every culture attitudes and values change and keep changing as equality principles progress. This change must be fostered and sustained. To fully tap into women's potential, the next decade should be devoted to implementing women's rights, to finding practical and effective ways to relieve their suffering, but also - and more profoundly - to redress the injustice that hampers, belittles and suppresses their contribution.

States have reiterated such conviction most recently in the course of the UN Durban Review Conference against Racism, Racial Discrimination, Xenophobia and Related Intolerance which took place in Geneva in April 2009. Seven paragraphs of the Outcome Document, the final pronouncement by the 182 Governments that attended the Conference, are devoted to supporting women in the realms of employment, migration, and assistance to victims of violence. Reinforcing the 2001 Durban Declaration and Programme of Action, the Outcome Document also aims to protect women against slavery, bondage and labour exploitation, and against human trafficking and violence.

To implement such an ambitious program, as well as the letter and the spirit of international human rights law, no effort should be spared to persuade countries to live up to their international obligations which enjoin them to repeal laws and stamp out discriminatory customs, harmful practices and prejudices that negate or undermine the achievement of equality between women and men. That is an indispensable starting point for the creation of a level playing field for women and girls, required for the achievement of substantive equality. It is also the pre-condition that underpins women's empowerment and their enjoyment of human rights.

The realisation of women's rights is predicated on the removal of all factors that hold women back, frustrate their resourcefulness, and curtail their access to a fair share of the common wealth.

It requires women's active participation in public life, their freedom of expression, association and movement, as well as the enjoyment of their rights to education, adequate food and housing, and the highest attainable standard of health, including reproductive health. It demands firm communal commitments to defeating fear and want.

Women's human rights and entitlements must ultimately be locked into national policies fostering self-help, opportunities, and solidarity. In this context, absorbing international standards into domestic law and enforcing them 
are of paramount importance. This adherence is indispensable to achieve women's equality in law.

I am very pleased to acknowledge that where CEDAW is concerned, 186 States are now party to this treaty, of which 97 are party to its Optional Protocol. South Africa is among them.

International human rights treaties prohibit discrimination on the basis of sex, and include guarantees to ensure that women and men enjoy their civil, cultural, economic, political and social rights on a basis of equality. Despite this prescription, global and national realities indicate that there is a wide gulf between international legal obligations and their implementation.

In 2005 the Commission on the Status of Women conducted a review of the commitments undertaken by Governments at the Fourth World Conference on Women in Beijing ten years earlier. It concluded that 'legislative and regulatory gaps, as well as lack of implementation and enforcement of legislation and regulations, perpetuate de jure as well as de facto inequality and discrimination'. Simply put, this means that women did not enjoy human rights on the basis of equality with men.

Inequality in the law exists in all regions of the world and in all legal traditions. In some countries married women are forbidden from keeping their own names, or passing their nationality on to their children. Their right to own land or inherit property may be limited, and their rights in marriage and divorce law are subjugated to the legal rights of their husbands. In other States, women do not have freedom of movement, and must be accompanied by male guardians. Their educational and employment prospects are heavily circumscribed, and they may be excluded from public office.

The Beijing +5 Review established 2005 as a target date for the revocation of laws that discriminate against women, but this deadline has come and gone; that call remains unheeded. Many of these laws are still in force and continue to be applied to the detriment of women and girls. The next decade should see meaningful movement towards total repeal of iniquitous legislation. This would be a long overdue remedy for women's plight, and a response to the plea of advocates all over the world.

Not only does inequality in the legal, civil, economic, political and social arenas violate international obligations, but it also compounds discrimination against women. When race, religion, ethnicity, poverty, disability, social status, and other forms of discrimination are also factored in, then the picture is one of even greater disparity.

Protecting women's rights in law and policies is particularly crucial when the economic going gets rough, as is the case now. Unquestionably, economic downturns jeopardise the full spectrum of women's economic and social rights. As economies head south, women are often forced to forego basic services to secure food and shelter. They see their job opportunities shrink and are forced to accept more marginal and ill-paid employment to make ends meet. Last month the International Labour Organisation warned that the global financial crisis could add an increasing number of girls to the more 
than 100 million who are already involved in child labour. Addressing the needs and critical vulnerabilities of women and girls caught in this recession is thus imperative. The economic stimulus packages that Governments are now devising must mitigate the effects of economic contraction, as well as jumpstart reforms in those public policies areas that address structural disadvantages. Thus, preventive initiatives, safeguards, as well as economic recovery and growth measures, must be designed to be gender-sensitive and non-discriminatory. They must be devised not only to address the immediate economic dire straits, but also to encompass longer-term measures to ensure that women's self-sufficiency and prosperity do not remain mere aspirations.

One thing is certain: times of hardship for families and communities expose women and girls to greater risks, since the venting of frustration and despair may increase the likelihood of violence against them. In a vicious cycle, violence against women compounds their vulnerability. As an advocate working against domestic violence, I have seen first-hand the impact of this violence on women, children, and families, wrecked by these crimes that are too often hidden and protected by impunity.

Allow me to reiterate at this juncture, that just as violence against women is a weapon of domination and an outlet for rage in the home, violence against women is a weapon of war in armed conflict. All too often perpetrators are not brought to justice and their victims receive no reparation.

Whether tactically motivated, or due to negligence or a misguided understanding of priorities and values, a State's abdication of responsibilities in upholding women's human rights is unacceptable. Decisive leadership and a sustained commitment are required to put an end to abusive practices and discrimination that hold women back.

In South Africa Dullah Omar and other visionary individuals have proved that, with the requisite political will, women's condition can be addressed and gender equality vigorously pursued. It was not an easy task, as the combined forces of patriarchy and apartheid had severely warped women's development and prospects while undercutting their rights.

Moreover, as opposed to the experience of other countries, in devising its own legislation and programs for the previously disadvantaged, South Africa had to tackle the paradox of how to create better opportunities, equality and justice for a majority of its population, rather than a minority. With regard to the status of women the situation was even more complex, because even though the apartheid regime had affected the rights of all women, not all women endured its effects in the same manner. Black and poor women, as well as lesbians, suffered disproportionately.

Ingeniously the government of Nelson Mandela linked institutional transformation to gender equality by opening up public sector opportunities to women. Building on constitutional principles and precepts, a pro-women legislative architecture was put in place. This included the Domestic Violence Act 116 of 1998 and the Recognition of Customary Marriages Act 120 of 1998. Today the country can be proud of its legal canvas that protects women's rights, as well as its comprehensive National Policy Framework for Women's 
Empowerment and Gender Equality. These developments have been influenced by CEDAW. Furthermore, institutions, such as, the Presidency Office on the Status of Women at the national level, and the Gender Departments at the provincial level, are mandated to carry out gender-oriented policies.

And yet here as elsewhere, as the poet William Blake said, "joy and woe are woven fine', since implementation continues to lag, regrettably, behind progressive laws. Certainly, this stems in part from the immense demands on the government's resources. But equally true is the fact that the original visionary impetus to substantive equality of the early post-apartheid era has lost its steam, if not its sense of determined purpose. Violence against women continues largely unabated. The 15,000 rapes reported every year might be just the tip of the iceberg. Constitutional protection of gay and lesbian rights has not prevented sexual violence against lesbian women. Not surprisingly, in this and in many other countries, women are the most affected by HIV and by poverty.

As we try to address these woes and pursue joy in the name, and for the sake, of all women in South Africa and elsewhere, we must focus on key aspects of implementation. In this regard I wish to point out once again that equality before the law loses its meaning when laws are not given full effect. By the same token, women's lack of access to justice, or a gender-blind or gender-insensitive judiciary, undermine women's right to equal opportunities and treatment. Ensuring that avenues of redress are open and permeable to women's needs, as well as attuned to their rights and plight, is a fundamental stepping stone towards the realisation of substantive, rather than merely formal, equality.

This observation leads me to the second point I would like to make regarding women's empowerment and the achievement of their rights. Such goals may also come to fruition through judicial processes, or be accomplished by mobilising international human rights protection systems, or they may be achieved through a combination of all these factors.

Undoubtedly, there has been a quantum leap forward in the prosecution of sexual violence before international tribunals. The jurisprudence of these courts represented a watershed for women whose wartime suffering had long been considered as an inevitable by-product of conflict, or as 'collateral damage' that could be more easily tolerated and, consequently, disregarded.

Through the work of international courts, we have been able to establish once and for all that — where threshold criteria are met — rape during international or internal armed conflict is a war crime, a crime against humanity, and may constitute an element of genocide. This was the conclusion reached in the Akayesu case ${ }^{2}$ before the International Criminal Tribunal for Rwanda. It was the first judgment on rape emanating from the ad hoc tribunals. This groundbreaking case, as well as the judicial rationale that supported it, found an echo in the local legislation of two states in the USA. In South Africa,

2 The Prosecutor $v$ Jean-Paul Akayesu Case No ICTR-96-4-T (Trial Chamber 1998). 
it resonated in the Criminal Law (Sexual Offences and Related Matters) Amendment Act 32 of 2007.

Justice mechanisms have been creatively and effectively used to ensure accountability in dire situations when Governments, in both poor and rich countries, have failed to guarantee women's enjoyment of their human rights, or where women's complaints were stonewalled by bureaucratic inertia and prejudice.

In a landmark 2004 case brought by interested parties and public interest groups before the Constitutional Court of South Africa, the court found that, in regard to inheritance, customary law governing succession was discriminatory on grounds of race, gender and birth. This ruling on inheritance conclusively proscribed discrimination against women, girl children and men other than the eldest male relative on the basis of race, sex, gender, social origin and birth. The decision may have multiple applications. For example, it may help assist widows and children to avoid eviction from the family home upon the death of a husband or father.

Increasingly regional courts have also been used to give effect to women's rights. I wish to bring to your attention two specific cases in Africa that are of particular interest.

In October 2008 the Community Court of Justice of the Economic Community of West African States (ECOWAS), a regional mechanism, held Niger responsible for failing to protect the rights of a young woman who, in 1996 at age 12 , had been sold to a 46 year-old man as his slave and concubine. ${ }^{3}$ After nine years of servitude and sexual violence, she was freed. She sought to rebuild a new life and start a family, only to incur the ire of her former 'master' who denounced her for bigamy. The woman was arrested, but fought back through all levels of the national judicial system. Finally, she petitioned the ECOWAS Court which ruled that the victim be compensated for Niger's dereliction of its duty to protect her.

In February 2009 the Special Court for Sierra Leone convicted three Revolutionary United Front rebel leaders of war crimes and crimes against humanity, including, the sexual enslavement of countless girls abducted from their villages. ${ }^{4}$ This was the first time that the forced marriage charge has been successfully handed down in an international court of law.

In June 2009 the European Court of Human Rights fined Turkey 36000 euros for its failure to protect two women from domestic violence that led to the killing of one of them in $2002 .{ }^{5}$ The authorities had considered the situation since 1995, but failed to take decisive action. Relying on CEDAW and case law stemming from its Optional Protocol, the court concluded that Turkey was in breach of various obligations under human rights law.

3 Hadijatou Mani Koraou $v$ The Republic of Niger Case No ECW/CCI/JUD/06/06 (2008).

4 The Prosecutor $v$ Issan Hassan Sesay, Morris Kallon aka Bilai Karim and Augustine Gbao aka Augustine Bao (RUF Case) Case No SCSL-04-15-t (Trial Chamber 2009).

5 Opuz v Turkey Case No 33401/02 (Sect 3) ECHR 2009 (9.6.09). 
In the years to come, as jurisprudence increasingly resonates from one jurisdiction to another across the world, these cases may be of great consequence, and furnish a model for courts in other regions and countries. Indeed, as it was observed in the course of a judicial colloquium that my Office organised in Bangkok last March:

'Members of the legal profession should be enabled to draw on the pertinent international human rights standards as well as the outputs of the UN human rights treaty bodies and regional human rights mechanisms in their arguments before domestic courts.'

Interestingly, participants in this colloquium also agreed that,

'where lacunae in the domestic law are identified, the judiciary should, as far as possible, resort to interpretations consistent with principles of international law and customary international law, as well as the meaning of international instruments'.

I want also to note, as a matter of regional pride, that the Protocol to the African Charter on Human and Peoples' Rights on the Rights of Women in Africa, may well in many respects be the most progressive articulation of women's rights in the world. South Africa has ratified the Protocol, and I know that Dullah Omar would have wanted South Africa to lead the way in ensuring full ratification and implementation of its provisions across the continent.

I mentioned my work in the definition of rape and sexual violence on the Rwanda Tribunal. I want to also mention the 'media case' I presided over, my last case as a judge on that Tribunal. ${ }^{6}$ In the media case we documented and recognised the powerful impact of the media on the genocide. The media promoted ethnic hatred and incited violence that exploded into genocide. I think we need to look much more seriously at the way in which the media treats women, and the impact of the media on violence and discrimination against women. The African Protocol specifically provides, as a matter of economic and social welfare rights, that Governments should take effective legislative and other measures to prevent the exploitation and abuse of women in advertising and pornography.

The media constitute a powerful force that can also be used for social justice, and that is where I think we should focus. Replacing oppressive stereotyping with positive role models will change the way both girls and boys grow up to think about each other and gender equality. And as the Protocol recognises, advertising needs particular attention, as the objectification of women is so often promoted by commercial advertisements. CEDAW, to which, of course, South Africa is also a party, provides that governments should take all appropriate measures 'to modify the social and cultural patterns of conduct of men and women, with a view to achieving the elimination of prejudices and customary and all other practices which are based on the idea of the inferiority or the superiority of either of the sexes or on stereotyped roles for men and women'.

6 The Prosecutor v Ferdinand Nahimana, Jean-Bosco Barayagwiza and Hassan Ngeze Case No ICTR99-52-T (Trial Chamber 2003). 
Historically, the United Nations has created a welcoming space for women to grow and compare notes, to build a grid of solidarity, and foster change.

Human rights mechanisms have often set the pace in spurring dormant national action. A case in point is that of the Committee that oversees CEDAW. Under its mandate the Committee has considered several cases where it concluded that States had failed to exercise due diligence in protecting women from marital violence. For example, in Austria, guidance from the Committee on legislative and policy measures fostered tighter law-enforcement procedures, and a more sophisticated understanding of domestic violence on the part of relevant authorities.

The influence of CEDAW, and the interaction with its Committee, can also be evinced from the application of temporary special measures which have led to women's expanded participation in public life and service. Rwanda, which established a system of quotas, now counts the highest representation of women in Parliament worldwide.

With regard to other human rights instruments and the work of the implementing treaty body, let me underscore that an important development has recently been added to the pertinent jurisprudence of the Committee on Economic, Social and Cultural Rights, that is, the mechanism devoted to the International Covenant on Economic, Social and Cultural Rights. In its new General Comment on discrimination, the Committee observed that, and I quote:

"Since the adoption of the Covenant, the notion of the prohibited ground "sex" has evolved considerably to cover not only physiological characteristics but also the social construction of gender stereotypes, prejudices and expected roles, which have created obstacles to the equal fulfillment of economic, social and cultural rights. Thus, the refusal to hire a woman, on the ground that she might become pregnant, or the allocation of low-level or part-time jobs to women based on the stereotypical assumption that, for example, they are unwilling to commit as much time to their work as men, constitutes discrimination. ${ }^{7}$

This comment is particularly momentous because it tackles multiple grounds of discrimination. It also places the question of sexual orientation clearly within the prohibited grounds of discrimination. Thus it provides a brave and powerful platform on which both jurisprudence and advocacy can further progress. It is my hope that South Africa will soon ratify the International Covenant on Economic, Social and Cultural Rights, which it signed in 1995, as well as its Optional Protocol when it opens for signature, accession and ratification in September. I take this opportunity to note that South Africa played an important role in the negotiations of this latter instrument.

For their part, independent human rights experts mandated by the UN, known as special rapporteurs, have been instrumental in fostering change and promoting protection. These experts are the international community's 'conveyor belts' of otherwise neglected human rights situations, and our

7 General Comment No 20 para 20. 
front-line advocates. In particular, I wish to commend the work of the Special Rapporteur on Violence against Women.

Moving now from well-honed and long-established United Nations mechanisms to innovative initiatives, let me draw your attention to the role that the Human Rights Council, the premier intergovernmental human rights body, can also play in fostering respect for women's human rights.

A groundbreaking feature of the Council is the Universal Periodic Review, a novel mechanism through which the human rights record and performance of all countries is examined at regular intervals. The Universal Periodic Review offers a new important space to civil society's contributions, including women's knowledge and perspectives. I exhort all women to take full advantage of this vehicle to convey their priorities, agendas and foremost concerns.

I also hope that the Council would expedite the creation of a mechanism to strengthen gender equality in national laws, and help repeal discriminatory legislation. Since 2005, this idea has been under consideration. In 2006, a report on the feasibility of such a mechanism by the Secretary-General concluded that ' $[a]$ dedicated mechanism that would tackle [discriminatory] laws as its primary and exclusive concern, rather than as incidental to a broader mandate, from a global perspective could provide the necessary momentum for change that has so far been absent'. Last year my Office presented a commissioned in-depth study on laws that discriminate against women, which examined the discussions on the creation of a dedicated mechanism. This study concluded that such a mechanism would be timely and helpful.

Allow me to underscore that the Security Council has also helped to foster a deeper understanding of the correlation between women's human rights and sustainable security. This understanding is mirrored in the Security Council's landmark Resolutions 1325 on women, peace and security, and 1820 on sexual violence in armed conflict.

Both on their own individual merit or taken together, and if properly implemented and enforced, these Resolutions will shore up efforts to better understand and address the human rights dimension in the causes, impact and resolution of armed conflicts. Given the priority they deserve, their provisions, which regard women as indispensible agents of change, will contribute to solidify peace, help justice take root, enhance equality, and ensure protection to the vulnerable.

As a step in the right direction, women should be granted a prominent role when peace agreements are negotiated, and in the aftermath of conflict. Regrettably, this has been the exception rather than the rule. Equally lamentable is the fact that, according to UNIFEM (the United Nations Development Fund for Women), less than six per cent of funds committed by donors after peace is restored are targeted in any way towards addressing women's needs.

These imbalances and inequities work against the letter and the spirit of the Security Council's will, and should be rectified as a matter of urgency.

Attention to the human rights of women, and ensuring that a gender perspective is integrated into the work of the United Nations human rights 
system and in national protection mechanisms, represent key priorities for OHCHR. My Office is dedicated to encouraging all States and stakeholders, as well as relevant national and international mechanisms, to focus on the promotion and protection of the human rights of women.

We strive to ensure that States implement appropriate laws, so that equal rights become a daily reality in the lives of all women. Thus, we focus on the promotion of all women's human rights, including their economic, social and cultural rights, which are also a means of securing women's participation in all aspects of governance. We work to combat sexual violence and to bring perpetrators to account. Rendering justice to the victims is not only a moral imperative, but also a legal obligation without which communal welfare is compromised.

Let me conclude by pointing out that, for all our woes, there are, of course, highly visible benchmarks of progress - women as heads of government, and in parliament, women leading the highest courts, and at the helm of businesses. Perhaps as a result, I see girls around the world growing up with a different sense of themselves than I and most women of my generation were given.

These girls are powerful - they say no to early marriage, female genital mutilation, and sexual violence. They want to go to school and get an education.

Governments and international organisations must meet their expectations and help them fulfil their goals. Empowering women and girls and creating an environment that is conducive to the realisation of their full potential is a responsibility and a priority of the tallest order now, and in the next decade. We must build on the progress achieved so far. Indeed, our past successes must be the prologue of our future advancement. 